\title{
EXPRESSÃO DO CONFLITO DE CLASSE NA CONCEPÇÃO DE EDUCAÇÃO PROFISSIONAL NO BRASIL CONTEMPORÂNEO
}

JOSÉ DOS SANTOS SOUZA ${ }^{1}$

Trataremos aqui aspectos teóricos dos diferentes discursos acerca da formação profissional nos anos 90. Para isso, tomamos como referência a teoria da práxis material em $\operatorname{Marx}^{2}$ como categoria analítica básica e seus pressupostos; são eles: 1) o trabalho como categoria central e determinante do processo histórico; 2) o trabalho como possibilidade de emancipação e desenvolvimento das potencialidades humanas; e 3) a possibilidade de superação da alienação do trabalho através da construção de uma nova hegemonia fundada na conscientização de classe e na luta pela superação das relações sociais de produção capitalista.

O ritmo e a direção do desenvolvimento dos sistemas educacionais no mundo contemporâneo é determinado pelo nível de desenvolvimento das

\footnotetext{
${ }^{1}$ Doutorando em Ciências Sociais pelo Instituto de Filosofia e Ciências Humanas (IFCH), da Universidade Estadual de Campinas (UNICAMP) e professor assistente da Universidade Estadual do Sudoeste da Bahia (UESB), onde coordena o Núcleo de Estudos e Pesquisas Sobre Trabalho, Política e Sociedade - NETPS.

${ }^{2}$ Ver, a este respeito, Karl Marx, Friedrich Engels, A ideologia alemã. São Paulo: Martins Fontes, 1989; Karl Marx, Capítulo inédito de O Capital - resultados do processo de produção imediata. São Paulo, s/d.; Karl Marx, "Manuscritos econômicos e filosóficos". In: Erich Fromm. Conceito marxista do homem. Rio de Janeiro: Zahar, 1970, $5^{\text {a }}$ edição, pp. 85-189; Karl Marx, O Capital. Rio de Janeiro: Bertrand Brasil, 1994, livro I, $14^{a}$ edição.
} 
forças produtivas e das relações de produção, assim como do nível de alargamento dos mecanismos de controle social das decisões estatais. Tais fatores, na atualidade, têm se consubstanciado no impacto econômico e políticosocial da aplicação da ciência e da tecnologia nos processos produtivos.

Nesse contexto, a educação profissional tem se constituído em uma ação de caráter técnico-político inerente ao processo de ampliação da maquinaria e de redefinição dos mecanismos de manutenção do consentimento operário. Entretanto, o estágio atual de desenvolvimento científico e tecnológico nos remete à consideração de dois aspectos: formação profissional, em sentido lato, e formação profissional, em sentido estrito. No primeiro aspecto a formação profissional refere-se às ações educativas que visam a conformação técnica, política e cultural da força de trabalho às necessidades da civilização urbano-industrial, presididas pela lógica científica da organização do trabalho e das relações de produção. Nesta perspectiva, formação profissional identifica-se com escolarização que,

“à medida que se amplia e se aprofunda a organização científica do trabalho e da vida, requer um patamar sempre mais complexo da capacidade de abstração do conjunto da força de trabalho, quer ela realize tarefas simples ou complexas no mundo da produção ou assuma responsabilidades sócio-político-culturais na organização do seu cotidiano"3.

A partir dessa consideração, o termo "educação básica" faz referência ao sentido lato da formação profissional, ou seja, faz referência à socialização da capacidade de produção do conhecimento científico e tecnológico minimamente necessário ao nível de racionalização do trabalho na indústria e à complexidade da vida contemporânea por intermédio da escola. ${ }^{4}$

${ }^{3}$ Lúcia Maria Wanderley Neves, Brasil ano 2000: uma nova divisão de trabalho na educação. Rio de Janeiro: Papéis e Cópias, 1997, p. 23.

${ }^{4}$ Tal concepção se confirma, inclusive, no texto da Lei 9394/96 quando trata das finalidades da Educação Básica: "Art. 22 A educação básica tem por finalidades desenvolver o educando, assegurando-lhe a formação comum indispensável para o exercício da cidadania e fornecer-lhe meios para progredir no trabalho e em estudos posteriores”. In: BRASIL. Lei 9394, de 20 de dezembro de 1996. Lei de Diretrizes e Bases da Educação Nacional. Vale observar que no projeto aprovado na Câmara de Deputados 
Já no sentido estrito, formação profissional no mundo contemporâneo refere-se a um ramo do sistema educacional destinado à atualização técnico-política e cultural permanente da força de trabalho escolarizada, após o seu engajamento potencial ou efetivo no mundo da produção. Seu principal objetivo é criar aptidões para o trabalho na sociedade urbano-industrial, por meio da permanente atualização técnico-produtiva da força de trabalho escolarizada. Neste aspecto, formação profissional identifica-se com ensino técnicoprofissionalizante ou, conforme o discurso oficial, educação profissional.

Assim, o termo "educação profissional" faz referência ao sentido estrito da formação profissional, ou seja, faz referência à atualização permanente da força de trabalho escolarizada para o domínio de aptidões técnicoprodutivas adequadas ao nível de racionalização do trabalho na indústria contemporânea 5 .

Tal concepção afina-se com o ideal de formação da classe trabalhadora para o domínio do conhecimento técnico-científico e filosófico socialmente acumulado para sua aplicação diretamente produtiva, através do processo trabalho. Ao ampliar-se a concepção de educação profissional, ela passa a ser vista como uma prática corrente do mundo contemporâneo que engloba desde a escolarização básica até ações educativas voltadas para o desenvolvimento de aptidões para a vida produtiva que se dá tanto no âmbito da escola regular quanto no âmbito das instituições de ensino profissionalizante, rompendo de uma vez por todas com a dicotomia entre educação profissional e escolarização, entre trabalho e educação.

Porém, considerando que o conflito capital/trabalho se materializa inclusive na concepção e na política de educação básica e educação profis-

tal vínculo com o trabalho também era atribuído à Educação Básica, demonstrando o nível de consenso acerca da questão.

${ }^{5} \mathrm{O}$ termo Educação Profissional é aqui utilizado para se referir à Formação Profissional em sentido estrito devido ao fato de ser esse o termo utilizado na atual LDB (Lei 9394/96). Veja: “Art. 39 A educação profissional, integrada às diferentes formas de educação, ao trabalho, à ciência e à tecnologia, conduz ao permanente desenvolvimento de aptidões para a vida produtiva". In: BRASIL. Lei 9394, de 20 de dezembro de 1996. Lei de Diretrizes e Bases da Educação Nacional. 
sional, é possível evidenciar dois projetos distintos, um da ótica do capital e outro da ótica do trabalho, sendo que ambos têm como pressuposto a aplicação da ciência e da tecnologia no processo de produção ${ }^{6}$.

De acordo com a ótica do trabalho, as exigências de formação e atualização da força de trabalho previamente escolarizada, decorrentes do avanço do patamar científico e tecnológico das sociedades contemporâneas, traduzemse num tipo de escolarização que engloba desde as habilidades técnicas necessárias ao domínio dos novos conteúdos do trabalho até os conhecimentos teóricos que favoreçam a compreensão do processo de trabalho em seu conjunto.

Na ótica do trabalho, portanto, a educação profissional seria um ramo da educação escolar, de natureza técnico-científica, espaço privilegiado para o aumento da capacidade produtora de ciência e de tecnologia. As proposições do movimento sindical para a educação profissional na atualidade impõem como objetivos, seja no âmbito da escola básica ou no âmbito dos Centros Públicos de Formação Profissional, o seguinte: identificar os princípios que presidem a relação ativa entre homem e natureza e a relação orgânica entre o indivíduo e os outros indivíduos ao longo da história da humanidade; apreender os fundamentos e os conteúdos do trabalho em determinado padrão de desenvolvimento científico e tecnológico da produção em nível internacional, de modo a intervir autonomamente nesse processo; solidificar uma consciência moral que atenda aos objetivos éticos de solidariedade e participação cidadã ${ }^{7}$.

\footnotetext{
${ }^{6}$ Esses dois projetos foram bem evidenciados na disputa eleitoral para a presidência da república em 1994 e em 1998 (Ver: José dos Santos Souza (coord.), Concepções e propostas educacionais em disputa no processo eleitoral de 1994 e 1998 - Relatório de Pesquisa. Vitória da Conquista (BA): Unesb/PPG, 1999; Luiz Antonio Cunha, Educação brasileira: projetos em disputa. São Paulo: Cortez, 1995). No campo sindical, por exemplo, esses dois projetos têm assim se consubstanciado: enquanto uma parcela do sindicalismo, representada pela CUT, vem disputando com o empresariado a hegemonia da sociedade, uma outra, representada pela Força Sindical, vem compondo com o empresariado nacional e o governo um bloco de parceria inspirado na colaboração de classes (Ver: José de Santos Souza, "Concepções e propostas da CUT e da Força Sindical para a educação brasileira - anos 90”. In: Lúcia Maria Wanderley Neves (org.), Educação e política no limiar do século XXI. Campinas: Autores Associados, 2000, pp. 79-102).
}

${ }^{7}$ Essa formulação está muito mais evidenciada nas resoluções dos congressos e plenárias nacionais da CUT a partir de 1994 (Cf.: Souza, "Concepções e propostas da CUT e da 
De acordo com essa concepção, as reivindicações para a universalização da educação básica e das oportunidades de educação profissional visam o aumento da produtividade industrial para maior qualidade de vida da população em geral, através do aumento do nível educacional de base científica e tecnológica do conjunto da população, diminuição da jornada de trabalho, aumento do tempo livre do trabalhador, garantia de acesso a bens e mercadorias indispensáveis à dignidade da vida humana.

Embora parta dos mesmos pressupostos da ótica do trabalho, na ótica do capital a educação profissional não assume caráter igualmente unitário. Embora seja impossível para as relações sociais de produção capitalista a radicalização da dicotomia entre teoria e prática no processo produtivo e de ciência e vida nas relações de produção, devido ao atual patamar de desenvolvimento das forças produtivas e da socialização da política, a ótica do capital procura impor limites à classe trabalhadora através da socialização desigual do conhecimento científico e tecnológico. Para isso, impõe objetivos diferenciados para educação profissional, seja no âmbito da escola básica, ou das instituições de ensino profissional. Para uma ampla parcela da força de trabalho prevê a conformação técnica e ético-política, capacitandoa para adaptar ou operar produtivamente as tecnologias produzidas; para outra parcela mínima da força de trabalho prevalecem os objetivos voltados para o domínio dos fundamentos e dos conteúdos do trabalho em determinado padrão de desenvolvimento científico e tecnológico da produção.

Desse modo, de acordo com a ótica do capital, a educação profissional baseia-se na distinção entre formação para o trabalho manual para a grande massa de trabalhadores e formação para o trabalho intelectual para uma elite privilegiada. No entanto, para ambas parcelas da força de trabalho, a educação profissional tem como objetivo a constituição de um novo tipo de cidadão voltado para o mercado, quer como sujeito empreendedor, quer simplesmente como sujeito de consumo. Nessa perspectiva, a formação profissional vem atender aos mecanismos sociais e políticos da reprodução das relações sociais fundadas na estrutura de dominação de classe.

Força Sindical para a educação brasileira - anos 90”, op. cit., 2000). 
Nessa última concepção, está implícito um modelo de desenvolvimento em que as reivindicações para a universalização da educação básica e para o desenvolvimento do ensino profissional visam o aumento da produtividade industrial para a valorização do capital.

Não obstante, tanto os sujeitos coletivos da ótica do capital quanto os da ótica do trabalho partem do pressuposto da aplicação diretamente produtiva da ciência e da tecnologia na organização do trabalho e da sociedade no mundo contemporâneo. No entanto,

"a explicitação dos dois projetos de sociedade, em disputa pela hegemonia na atualidade brasileira, põe em evidência as diferenças existentes entre a proposta de educação pública e gratuita com qualidade para todos em todos os níveis e a proposta de educação básica de qualidade para a competitividade industrial" ${ }^{18}$.

No Brasil atual, o projeto de sociedade da ótica do capital tem atribuído à educação o papel de formação e qualificação da força de trabalho com base em um patamar mais avançado de uso diretamente produtivo da ciência e da tecnologia no trabalho e na vida urbano-industrial, com vistas à garantia de maior produtividade e qualidade da indústria nacional como diferencial de competitividade no mercado dito globalizado. Para isso, tem sido obrigada a explicitar os vínculos da educação com o mundo do trabalho dentro dos limites impostos pelo atual patamar de desenvolvimento do capital. Assim, embora a redefinição da política educacional brasileira nos anos 90 não esteja voltada para a garantia da qualidade de vida, não se pode negar que ela tem aberto novas possibilidades para a emancipação da classe trabalhadora, na medida em que pressupõe a universalização da Educação Básica, diminuição da dicotomia entre teoria e prática, trabalho e educação, ciência e vida, bem como pressupõe maior socialização da política obtida pela redefinição da ação do bloco no poder em busca do consenso junto às massas em torno de seu projeto de sociedade como forma de manutenção da hegemonia.

Por outro lado, o projeto de sociedade da ótica do trabalho ainda hoje não concebe a educação escolar enquanto formação e qualificação da for-

\footnotetext{
${ }^{8}$ Lúcia Maria Wanderley Neves, (cood.). Política educacional nos anos 90: determinantes e propostas. Recife: Editora Universitária da UFPE, 1995, p. 114.
} 
ça de trabalho, sob o paradigma da concepção ampliada da formação profissional, na medida em que ainda não explicita seus vínculos com o "mundo do trabalho", freqüentemente tratando a educação básica de forma desvinculada da educação profissional ${ }^{9}$. O maior vínculo verificado até o momento presente tem se consubstanciado na proposta dos Centros Públicos de Formação Profissional, que consiste na luta pela oferta de ensino profissionalizante por instituições públicas sob o controle dos trabalhadores e na oferta de cursos profissionalizantes promovidos pela CUT com recursos do FAT, com vistas 'a garantia de emprego e renda. Ainda assim, não apresenta clareza no reconhecimento da unidade entre a educação básica e educação profissional enquanto luta pela superação da dicotomia entre teoria e prática, ciência e vida, trabalho e educação, com vistas à formação omnilateral do trabalhador.

\footnotetext{
${ }^{9}$ Ver, por exemplo, as proposições da CUT para a educação básica e para a educação profissional nas resoluções de congressos e plenárias nacionais realizadas a partir de 1994. A tendência tem sido tratar esses dois campos da formação da classe trabalhadora cada vez mais como políticas distintas, com objetivos e metas diferenciados (Cf.: Souza, "Concepções e propostas da CUT e da Força Sindical para a educação brasileira - anos 90", op. cit., 2000).
} 